DOI: http://doi.org/10.21698/simi.2018.ab04

\title{
ECOLOGICAL TECHNOLOGIES FOR BAUXITE RESIDUE STORAGE AND VALUE OPPORTUNITIES FOR ITS USE IN CHEMICAL AND CIVIL ENGINEERING PURPOSES
}

\author{
Gheorghe Dobra ${ }^{1}$, Laurentiu Filipescu ${ }^{2}$, Nicolae Anghelovici ${ }^{1}$, Sorin Iliev ${ }^{1}$, Vicol Alistarh ${ }^{1}$, \\ ${\text { Lucian } \text { Cotet }^{1} \text {, Alina Boiangiu }}^{1}$ \\ ${ }^{1}$ Vimetco Alum, 113 Isaccei, Tulcea, dobra@alro.ro, Romania \\ ${ }^{2}$ Politehnica University of Bucharest, 313 Splaiul Independentei, 060042, Bucharest, Romania
}

Keywords: bauxite residue, corrosivity

In this paper will be presented some of the environmental programs developed by Vimetco Alum SA Tulcea, Romania during last 10 years, in order to identify and apply the appropriate ecological technologies for storage and valorization of the bauxite residue. These programs can be grouped in 3 main categories: A) Multi-annual programs for the construction, maintenance and alignment of the bauxite residue storage site in respect with the ecological and international safety standards; B) Multiannual programs for the complete analysis and characterization of Sierra Leone bauxite and its Bayer processing by-product, the bauxite residue; C) Multi-annual programs to investigate the possibilities of simple and complex use and valorization of bauxite residue. The last category encompasses the following investigations: a) Effects of bauxite residue bulk drying and carbonation at the surface of disposal site on its chemical properties and corrosivity, and b) Preliminary processing of the bauxite residue for use as raw materials in road infrastructure construction, which are the subject of this paper. The objectives of these researches were: a) deep understanding of all the bauxite residue physico-chemical and mechanical properties and the variation of these properties in the course of production and storage, and $b$ ) preparation of the bauxite residue as raw material for use in various applications. 